Article

\title{
Growth of Firms in a Fragmented Cultural Industry: Italian Commercial Art Galleries' Competitive Strategies
}

\author{
Donatella Depperu ${ }^{1, *} \mathbb{E}$, Giacomo Magnani ${ }^{1}$, Lisa Crosato ${ }^{2}$ and Caterina Liberati ${ }^{3}$ \\ 1 Department of Economic and Business Management Sciences, Università Cattolica del Sacro Cuore, \\ 20123 Milano, Italy; giacomo.magnani@unicatt.it \\ 2 Economics Department, Università Ca' Foscari di Venezia, Dorsoduro 3246, 30123 Venice, Italy; \\ lisa.crosato@unive.it \\ 3 Department of Economics, Management and Statistics (DEMS), Università degli Studi Milano Bicocca, \\ 20126 Milano, Italy; caterina.liberati@unimib.it \\ * Correspondence: donatella.depperu@unicatt.it
}

Citation: Depperu, D.; Magnani, G.; Crosato, L.; Liberati, C. Growth of Firms in a Fragmented Cultural Industry: Italian Commercial Art Galleries' Competitive Strategies Sustainability 2021, 13, 5057. https:// doi.org/10.3390/su13095057

Academic Editor: Danuta Zawadzka

Received: 10 March 2021

Accepted: 27 April 2021

Published: 30 April 2021

Publisher's Note: MDPI stays neutral with regard to jurisdictional claims in published maps and institutional affiliations.

Copyright: () 2021 by the authors. Licensee MDPI, Basel, Switzerland. This article is an open access article distributed under the terms and conditions of the Creative Commons Attribution (CC BY) license (https:// creativecommons.org/licenses/by/ $4.0 /)$.

\begin{abstract}
The growth of cultural firms is important in developing local economies, enhancing employment, and improving urban sustainability, but it is difficult to achieve in fragmented industries that are populated by the smallest firms and offer a particularly unfavorable context for growth. The study takes a contingency perspective and contributes to both the literature on business strategy in fragmented industries and that on the growth of small and medium-sized enterprises (SMEs) by identifying the strategies implemented in a fragmented cultural industry, determining which of them are associated with a firm's expected growth, and finding the few firm-specific factors that are associated with growth. It also complements the extant literature on art galleries by looking at them from the understudied strategic perspective. Suggestions for practitioners and policy makers are included.
\end{abstract}

Keywords: firms' growth; competitive strategies; cultural industries; art galleries; fragmented industries; urban sustainability; cluster analysis

\section{Introduction}

Small and medium-sized enterprises (SMEs) are considered the engine of job creation and local economic development [1] and are therefore crucial to both developing and developed economies [2,3]. This is particularly true for SMEs operating in cultural industries, as they have a social role beyond their economic one, not only improving the economic welfare of the areas where they are located but also positively contributing to the quality of urban life [4,5]. In cultural industries especially, however, which suffer more than others from a lack of managerial skill [6], the economic sustainability of SMEs can be fragile due to limitations related to their size [7-9]. Growth can therefore represent a strategic goal for ensuring sustainability over time, making SMEs resilient to the threats of competition and the characteristic uncertainty of cultural and creative industries $[10,11]$.

Cultural industries are populated mostly by SMEs and, in some cases, by smaller micro firms [12], defined by the European Commission [13] as those with fewer than 10 employees. For all these firms, understanding which competitive strategies to follow for growth is crucial, as their small size makes it difficult to implement the range of strategies that have been identified in research on larger firms. Therefore, studies are needed that look at SMEs and micro firms, including those competing in fragmented industries (i.e., industries in which no competitor has a sufficient market share to influence its competition) [14]. While it is accepted that SMEs are different from large firms [15], as stressed by Singh et al. [16], there has historically been a lack of empirical research on their strategies.

Commercial art galleries (henceforth, art galleries) do not produce artworks but are traders of artworks. Consequently, artists are their "suppliers". According to the European 
Commission [12], art galleries, as art traders, are included among the six functions of the cultural sector, which is part of the cultural and creative industries (also see Roodhouse [17]). They provide an interesting context for analyzing competitive strategies and firm growth not only because of their cultural dimension but also because they are part of an industry that is fragmented worldwide [18] and in which growth is particularly challenging.

Among the focus and niche strategies (based on specialization), business strategy scholars have traditionally identified those that can be implemented in a fragmented industry $[14,19]$. They have also highlighted that acquisitions and cooperative agreements are important means of growth in such industries [14,20,21]. It is unclear, however, whether those strategies prevail in the art gallery industry and represent "the" way to compete. More specifically, we do not know whether art galleries tend to employ only focus or niche strategies or which specific competitive strategies are associated with their growth. Furthermore, while the literature on the growth of SMEs has identified important variables within a set of internal factors that can be correlated to growth (for example, type of firm strategy or ownership) [22-25], we do not know which of them are relevant for art galleries, as few researchers have focused on their strategies and managerial choices with few exceptions [26-28]. Filling this gap is important not only to extend and test theory in cultural sectors and industries but also because smaller cultural firms often lack the necessary managerial competencies to autonomously identify which strategies are more appropriate for effective competition and growth. Said differently, there is a practical need to better understand such firms to enhance their success and growth and facilitate the positive impact they can have at a higher level. Indeed, as art galleries are part of the cultural industry, their growth may be an important target for policy makers as shown by the European Union's interest in national and regional bodies' support of cultural firms' competitiveness and growth [29]. Furthermore, art galleries share managerial concerns with traders that compete in similar markets (such as retailers of antiques or of designers' and artisans' products) and that could benefit from a study of art galleries.

This early study, through a survey of the owners or managers of a sample of Italian art galleries, aims to answer the following research questions: which competitive strategies are implemented by proactive art galleries and, in particular, which competitive strategies do characterize growth-oriented art galleries? Do growth-oriented art galleries follow a consolidation strategy? Which internal structural factors of art galleries are correlated with expected growth?

We discovered a typology of competitive strategies that include, but are not limited to, the focus and niche strategies that have typically been considered for fragmented industries; from a methodological standpoint, the competitive strategies revealed by a cluster analysis were subsequently employed among the independent variables in a Logistic Regression aimed at explaining expected growth. We found that most growth-oriented art galleries follow a focus strategy that combines cost and differentiation advantages, that they are not more oriented toward consolidation than others, and that only a very limited number of firm-specific factors affect art galleries' expected growth.

This study contributes to the literature on strategy by testing and complementing studies that approach competitive strategies from a contingency perspective (specifically, those that look at firm strategy in combination with an industry's characteristics, such as [30]) by applying them to SMEs and micro firms that compete in a fragmented cultural industry. We also identify which strategies and firm-specific factors are associated with the expected growth of art galleries, providing lessons for them and perspectives for future research. In doing so, we extend to a cultural industry the analysis of the impact of internal factors on the growth of firms. Finally, we offer suggestions for practitioners and for policy makers who aim to enhance art galleries' growth as a way to improve the quality of urban life and enhance economic development at the local level.

The paper is structured as follows. Section 2 describes the main features of art galleries and the art gallery industry, and Section 3 reviews the literature on strategies for competing and growing in fragmented industries. Section 4 describes the methods, and Section 5 
provides the results. A discussion, policy implications, and advice for practitioners are offered in Section 6, followed by the conclusion in Section 7.

\section{Art Galleries}

A work of art can be bought directly from the artist or owner without an intermediary, from auction houses, from private dealers or galleries (public dealers), or, for certain categories of goods, from web-based intermediaries, such as eBay [31]. Thus, galleries are part of the art market along with major auction houses, smaller auction houses, and collectors who sell works of art directly [32]. The role of galleries in the art market was established in the 1880s [33], when galleries, as dealers, became a driving force in the art system. For over a century, they have played a central role for artists needing to reach potential customers [28], representing the most effective known channel [34].

Art galleries are recognized as playing a social and cultural role. First, they are considered public dealers (in contrast to private dealers) because the public is invited to visit their exhibitions even without intending to buy. By thus increasing access to the artists work, they serve as cultural agents in society, as do public or non-profit organizations, such as museums and archeological sites. Second, due to their double dimension as business and cultural players, they contribute to improving the quality of urban life, attracting artists who can be drivers of gentrification [35] and, as retailers, having a social impact in terms of urban resilience and urban sustainability [36].

According to the European Fine Arts Fair [18], art galleries are typically SMEs, and the great majority are one-person firms (in which the owner is the only worker). This is because the main resources required to compete in this industry are competencies rather than financial resources, so SMEs and micro firms can survive and compete effectively. Additionally, sales tend to be erratic, so personal relationships and the ability to advise artists are crucial and more important than size. Finally, the entry barriers are low. Although size is not a key success factor for art galleries, larger firms can exploit their greater financial resources to buy many pieces of art from the same artist, broaden the range of their offerings, and recruit viable artists, thus taking advantage of economies of scale. As noted by Caves [37], the "dealer gains a critical mass advantage in drawing the attention of art writers" [37] (p. 46) and other opinion leaders, can use diverse communication channels to establish and maintain contact with customers (including those abroad), and can develop and support its brand name, widening its geographic scope. These advantages are important in the context of macro trends that have recently affected art galleries globally, such as the increasingly prominent role of social networks, the globalization of tastes and clients, the growing importance of art fairs (most of which have become brands), and the introduction of new regulations.

Art galleries are subject to the so-called nobody knows property [37], which makes them highly dependent upon customers' tastes and requires flexibility. Firms operating in cultural industries face high uncertainty and a constant oversupply of creative labor [11], which affect not only those who produce artworks but also distribution channels. For galleries, this means having to choose from a vast number of artists and artworks that they will offer to their customers while competing with differentiated competitors and deal-ing with extremely uncertain and unpredictable demand. In galleries, we find two distinct dimensions that are always in dialogue with each other: the capitalistic one, which is typical of every kind of business, and the aesthetic one, which, as noted by Crane [38], is typical of cultural institutions. Consequently, an art gallery's value proposition is multifaceted. It comprises the accumulated works of art that the gallery presents and sells, the range of artists and products it offers, the services it offers to visitors and collectors (such as seminars, meetings with artists, and temporary exhibitions), and other peripherals, such as the receptions it organizes and the catalogues and papers it prints. Robertson and Chong [31] emphasize that these dealers have three levels of consumption and diverse types of consumer: spectators, collectors, and investors/speculators. Art galleries, in 
addition to dealing with uncertainty and the evolving variety of customers' tastes, must also address concerns related to competing in a fragmented industry.

\section{Literature Review of Competitive and Growth Strategies in Fragmented Industries}

A fragmented industry has been defined as "an industry in which no firm has a significant market share and can strongly influence the industry outcome" [14] (p. 191). In fragmented industries, both entry and mobility barriers are low, resulting in a zerosum or negative-sum game that is characterized by head-on competition among firms for resources and customers [39]. The economic sustainability of firms competing in a fragmented industry can therefore be challenging, especially for those with a cultural dimension and therefore a cultural and social role, as the negative consequences of failure can be relevant not only at the firm level but also at the local level. It is therefore useful to identify which strategies are associated with growth, as growth strengthens firms, makes them more resilient to threats, and benefits the economic welfare of society.

Below, we summarize the literature that is relevant to our study, considering competitive strategies in fragmented industries, growth strategies in fragmented industries, and firm-specific structural factors that are correlated to firm growth.

\subsection{Competitive Strategies in Fragmented Industries}

The literature on competitive strategies in fragmented industries is scarce and has been shaped mostly by Porter [14], who was the first to identify strategic moves to cope with fragmentation. Fragmentation is considered a relevant industry feature that should affect the choice of appropriate strategy from a contingency perspective [30,40], that is, a perspective from which not all strategies are equally effective in a given environment. Stemming from organizational studies on leadership [41] and known for the emphasis on the relationship between strategy and structure [42], the contingency theory posits the importance of the fit between environmental (external) and firm (internal) factors as an explanation for firm performance. Therefore, specific characteristics of the environment would require different firm structural characteristics $[40,43]$, and changes in the environment would require firm structural changes to reach a new fit and a better performance [44]. As fragmented industries are characterized by specific features, not all strategies and structures are considered appropriate. While the contingency theory was developed looking at large firms and to their organizational structure, when we consider small and micro firms, we do not find significant differences in terms of organizational structure. Micro firms, for example, tend to have a flat, horizontal structure with few employees and are centered on the owner [45], regardless of their industry and strategy. However, small and micro firms can differ as far as other internal structural characteristics linked to their competitive strategies are concerned. According to Porter [14], strategies for dealing with fragmentation can use a group or network structure (tightly managed decentralization and "formula" facilities), specialization (by product type or segment, by customer type, and by type of order), focus (on a geographic area), cost control (bare bones, no frills), or backward integration. Most of the strategies identified by Porter are characterized by focus and specialization and, together with a cost leadership and differentiation strategy, represent Porter's generic competitive strategies. Therefore, employing Porter's approach, we would expect a focus or niche strategy to be implemented in a fragmented industry. This is consistent with other research on SMEs, for example, $[46,47]$ that recognizes that many small businesses, i.e., the key players in a fragmented industry, lack resources and have no other option than to implement focus strategies. Therefore, they tend to target geo-graphic-, product-, or service-based niches that they perceive to be less complex and more stable while avoiding uncertain environments in which they may achieve suboptimal results [48]. Other researchers, by contrast, have found that smaller firms sometimes do not follow the generic focus strategy of Porter, who, based on a single type of competitive advantage (cost vs. differentiation), identified either a cost focus or a differentiation focus strategy. These researchers have shown that SMEs can pursue both types of advantage 
simultaneously. For example, Leitner and Güldenberg's [49] study of small Austrian firms found that a combination strategy can succeed, underlining the positive role of technologies in allowing small firms to be simultaneously cost- and differentiation-oriented. Similarly, Miller and Dess [50] found that firms combining differentiation and price leadership were the most successful across industries.

Consistently with what the literature on this topic suggests, we expected art galleries to pursue either a focus or a niche strategy, as they are SMEs and micro firms that compete in a fragmented industry, and to find that some art galleries seek to combine a cost focus with a differentiation focus in facing their competitors. We did not expect to find any broad scope strategy.

We formulated the following hypothesis:

HP1: Art galleries will use either a focus strategy or a niche strategy based on one type of competitive advantage or will use focus and niches strategies that combine cost and differentiation advantages but will not use broad scope strategies.

\subsection{Growth Strategies in Fragmented Industries and the Role of Firm-Specific Structural Factors}

For firms competing in fragmented industries, a key objective is overcoming the challenges related to fragmentation, which some of the literature on fragmented industries suggests can be achieved through consolidation. Indeed, some researchers have identified consolidation via M\&As or cooperative agreements as a way to effectively compete and grow in a fragmented industry. Dollinger [20], for example, posits that collective strategies are possible in fragmented industries, albeit less visibly than in concentrated industries, suggesting that SMEs in fragmented industries can, in aggregation, find a way to compete with other SMEs. Additionally, Hill and Jones [21], underlining the related advantages, describe four strategies for the consolidation of fragmented industries: chaining, franchising, horizontal mergers, and use of the internet. In pursuing these strategies, many small businesses aggregate or consolidate into one entity. This, according to Resch [27], is occurring among some art galleries adopting new business models. Aggregation and consolidation can increase the number of customers addressed, broaden the range of products offered by firms, and extend the target geographic market. In many industries, all these objectives have organically become easier to achieve through use of the internet as both a marketing tool and an e-commerce channel. This is not common in fragmented industries, however, in which firms rarely evolve beyond the minimum size. This is in line with the idea that the "munificence" and dynamism of the environment, including the intensity of competition, play a relevant role in growth, especially organic growth [51]. Therefore, achieving organic growth is particularly challenging in a fragmented industry. However, Porter [14] suggests that overcoming fragmentation is possible when a firm, eliminating some factors that underlie fragmentation, manages to exploit economies of scale and experience.

Based on the important role that consolidation can have in overcoming fragmentation, we expected that growth-oriented art galleries would be more oriented toward consolidation than others. We therefore formulated the following hypothesis:

HP2: Growth-oriented art galleries will be more consolidation oriented than others.

The literature on the growth of SMEs and micro firms is mostly entrepreneurship literature, focused on the role that entrepreneurs and their orientations play in firm performance. Less research examines the impact of firm strategies and firm-specific factors on their growth, particularly in the case of SMEs and micro firms (for a summary, see Davidsson et al. [22] and Gupta et al. [24]). Studies taking this perspective, sometimes achieving mixed results, have identified the antecedents of growth in firms' strategies and internal factors, such as a firm's age, size, location, legal form, ownership, and competencies [22,51-54]. For example, in some studies, age has been found to relate negatively to growth $[55,56]$, suggesting that younger firms grow more rapidly than older ones but, un-like older ones, must be aggressive in terms of marketing to succeed [51]. Size is a controversial antecedent of growth; while some researchers have found a negative correlation of size with growth, others have found a positive one, and some evidence suggests 
that age and size negatively affect the growth of only young SMEs [57]. Similarly, other factors, such as location, ownership, and competencies, have been found to affect firm growth [22,25,58-61]. Location is crucial for small retailers [62,63], and various locations can impact firm performance. Regarding family ownership, the results of previous studies are mixed $[23,25]$ and reflect the double-edged role of families as owners. On the one hand, they can have a positive role by guaranteeing continuity and a long-term perspective, while, on the other, it is recognized that families often do not pursue growth but instead privilege firm survival and socioemotional wealth, seeking to avoid the risk of losing control of the firm $[64,65]$.

In the resource-based view of firms, we can see competencies as unique resources that can positively affect performance through the development of a competitive advantage [66]. We must consider, however, that various competencies are relevant depending on the industry or type of firm and that some studies have found evidence that, under specific conditions, better performance depends on a wide spectrum of competencies [67]. In the art gallery industry, there are reasons to suspect that the internal factors mentioned above are also relevant for art galleries. For example, location (city center vs. periphery) should be relevant in terms of firm image, accessibility, and costs, while size could be a proxy for resources that a firm can rely on, and specific competencies may be positively correlated to growth. As we found no specific suggestions in the literature regarding art galleries, however, we conducted an exploratory analysis to determine which of the strategies implemented by art galleries and which firm-specific factors (drawn from the litera-ture on growth) affect an art gallery's expected growth. To those existing factors, we added the existence of cooperative agreements, both because they have long been found to be positively correlated to small firms' and retailers' growth [68] and because they have emerged as factors relevant to consolidation in fragmented industries, including in some studies on the business models of art galleries [27]. We also considered the gallery type [69], a firm-specific factor that characterizes firms in this industry.

\section{Methods}

\subsection{Research Design and Sample}

To analyze the strategies of art galleries and answer our research questions, we focused on the Italian market. Italy is traditionally a leading country in the visual arts and plays an important role in the art trade. As in other countries, the Italian art gallery in-dustry is fragmented, even though the number of galleries is declining (Figure 1). In 2018, Italy had 1990 art galleries [70], most of which were traditional, one-person firms that, primarily because of their very small size, we did not expect to be of particular analytical interest from the strategy and growth perspective. Consequently, a sample of art galleries was selected that included the 319 art galleries that could be considered proactive, as they participated in at least one of the five important Italian fairs (Artissima, Miart, Mia Photo, ArteFiera, and ArtVerona) [71-75] in the period 2016-2017. Participation in such a fair requires financial resources and competencies that are also important for growth. Therefore, galleries that participate in fairs offer a good sample for studying growth strategies and may serve as a benchmark for the others.

Worldwide, mainly due to firm size, there is a degree of opaqueness in the art gallery industry. Consequently, it is very difficult to get information on galleries' performance [18]. This is true in the Italian market, so using secondary data as a source for our study was excluded from the beginning for that reason and because this study looks at strategies and their expected impact on growth. We therefore conducted a survey to obtain information on expected growth as well as qualitative information on the strategies imple-mented by the sampled art galleries. 


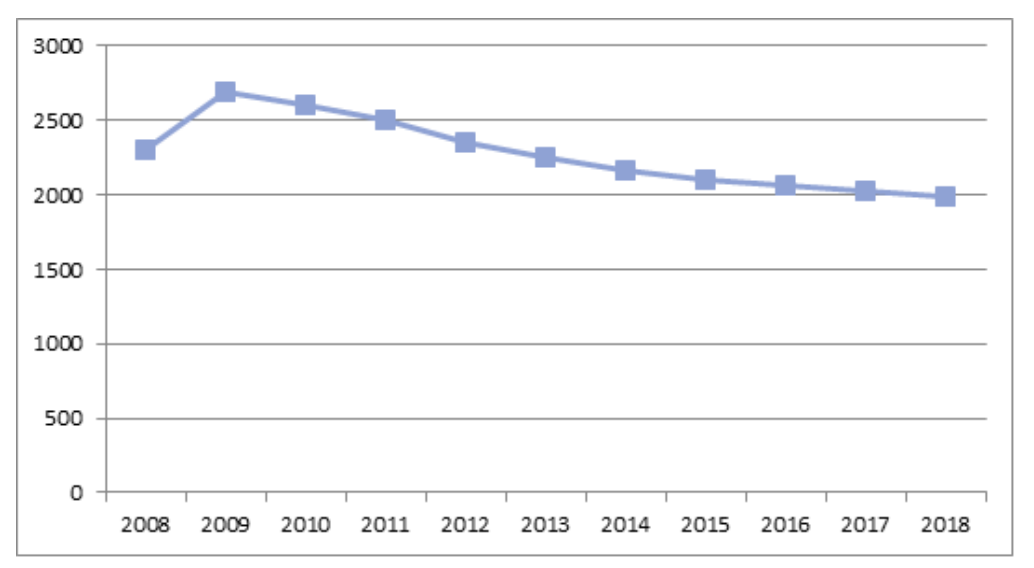

Figure 1. Number of art galleries in Italy, 2008-2018. (Source: Infocamere).

A rather long questionnaire was developed and submitted to the owner or manager of each art gallery, accompanied by a short explanation of the study's objective. The response rate was $32.6 \%$, with a total of 104 valid questionnaires. In this survey, we asked many questions and collected data and information on the art galleries' features, institutional choices, customers, products and services, resources, and perceptions of their own competencies. Perceptions are relevant in the development of strategy, as they drive top managers' decisions and affect strategy formulation (for a literature review on the topic, see Özleblebicia and Çetin, [76]), so we considered them relevant to understanding and classifying the art galleries' strategies. We also gathered information about expected sales revenue trends for the next three years (2018-2020) to determine which strategies are associated with expected growth and to identify which firm-specific factors can enhance or hinder growth. Our sample is homogeneous in terms of industry but heterogeneous in terms of strategies, business models, and growth expectations.

\subsection{Data Analysis}

The data analysis was conducted in three stages: selection and reduction of variables, cluster analysis, and logistic regression.

(a) Selection and reduction of variables

According to Porter [14], competitive strategies can be classified based on firm scope and competitive advantage, which leads to the identification of the following generic competitive strategies: cost leadership, differentiation, cost focus, and differentiation focus. In looking at competitive strategies for fragmented industries populated by SMEs and micro firms, however, and consistently with the literature summarized in Section 3, we considered that such firms tend to be characterized by specialization or by a focus on product type, product segment, customer type, type of order, or geographic area. To consider both the generic competitive strategies and the specialization of firms, this study selected 12 variables (some of which are specific to the industry) to classify the strategies implemented by the sampled firms. Eight of the variables-gallery area, number of branches, percentage of primary market, minimum price charged, number of artists dealt with, range of artworks sold, range of services offered, and intensity of services-referred to the value proposition and were used to analyze the orientation to cost or differentiation of the galleries. The other variables (percentages of large collectors, investors, small collectors, and occasional customers) provided information on the weight of various customer segments and were therefore used to characterize the galleries' strategies based on the broadness of their scope. These variables represent the dimensions used to establish a taxonomy of competitive strategies in the art gallery industry by means of a cluster analysis.

To avoid potentially controversial aspects of cluster analysis, such as multicollinearity [77], a Principal Component Analysis (PCA) was carried out [78,79], as Bartlett's test of sphericity $\left(\chi^{2}=267.199, \mathrm{df}=66, p\right.$-value $\left.=0.00\right)$ rejected the null hypothesis of no correlated 
variables. The solution with seven factorial axes, explaining approximately $80 \%$ of the total variance, was retained. The seven principal components (PCs) were then used as input variables for the strategy classification study.

(b) Cluster analysis

To develop a taxonomy of the sampled art galleries' strategies, we performed a cluster analysis, a type of analysis used mainly in early and exploratory studies [48]. In clustering strategies, the dissimilarities among instances are calculated according to Euclidean distance. The choice of this metric was appropriate because, as the principal components were uncorrelated, no further weight of variable redundancy was needed. Based on this distance matrix, a hierarchical algorithm (using Ward's method) was then applied to form the clusters, assigning each gallery to a specific group. A clear solution with a fixed number of separated groups was not immediately recognizable, so the Silhouette Index (SI) [80] was calculated to rank possible alternative partitions.

The SI contrasts cohesion within clusters and separation between clusters by comparing the similarity of each instance to its own cluster and to other clusters. The SI value for each instance ranges from -1 to +1 ; high positive SI values indicate a good match between the instance and the assigned cluster, while the opposite indicates a poor match. The synthetic measure for the sample was obtained by averaging the single instances' values.

Table 1 shows the average values of the silhouette for various partitions, with a maximum number of clusters equal to seven. According to the results, the best solution (corresponding to the maximum value of SI) was the one composed of five groups.

Table 1. Number of clusters with corresponding values of the silhouette index.

\begin{tabular}{cc}
\hline Number of Clusters & Silhouette \\
\hline 2 & 0.0968 \\
3 & 0.1082 \\
4 & 0.0976 \\
5 & 0.1206 \\
6 & 0.1102 \\
7 & 0.1043 \\
\hline
\end{tabular}

The clusters identified at this stage were described using the variables summarized in the PCs and were further qualified through additional variables, most of which related to the firms' structures. The second stage was crucial for characterizing the strategies identified by the clusters.

(c) Logistic regression

In the third stage, the impact of the observed strategies on growth was investigated using a forward-looking perspective. Therefore, a logistic regression was estimated in which the dependent variable was a subjective evaluation of the sales growth expected by the respondents. The dependent variable expected growth has been coded in terms of expected sales growth for the three years after the survey; it takes the value 1 if sales are expected to grow in the next three years and the value 0 otherwise. Growth has often been operationalized in terms of sales increase $[30,54,81]$, and we have done the same.

Consistently with the literature summarized in Section 3, we used as independent variables the type of strategy implemented (using the five competitive strategies emerging from the previous cluster analysis) and several firm-specific factors potentially relevant to growth: type of gallery, location (center/periphery), legal structure, ownership (measured as family/non-family gallery), presence of agreements (equity agreement, non-equity agreement, equity/non-equity agreement), presence of competencies (marketing, sales, art management, graphic/communication, artistic), gallery age, and gallery size (measured by the number of employees).

Candidate variables were selected using a backward procedure. The procedure started from the complete model with all the regressors, and, at each step, the least significant variable was removed. Rather than using the standard level of significance (alpha $=0.05$ ), 
we set alpha at 0.1 to balance bias and the small sample size [82]. The removal testing, based on the probability of the likelihood-ratio statistic, eliminated several variables, so the final regression resulted in a limited subset of variables.

\section{Results}

The first result of the analysis is represented by a taxonomy of the strategies carried out by the sampled art galleries. Five strategies emerged from the analysis, each corresponding to a specific cluster and characterized by both the variables used to obtain the clusters (Table 2) and relevant internal characteristics (Table 3). We also report some variables leading to nonsignificant comparisons among the clusters to provide a more complete characterization of the strategies.

Cluster 1: Cost and differentiation focus strategy

This cluster contains 33 art galleries (32\% of the sample) with an average size of 1.70 employees. Their competitive strategy is defined as cost and differentiation focus as characterized by both a low minimum price charged and a small-medium range of products and services (the range is not great because, for example, the galleries are less oriented than others toward supplying face-to-face services, such as meetings and seminars). Art galleries in this cluster operate mainly in the primary market (i.e., they buy artworks di-rectly from artists) and deal with a low number of artists. Regarding geographic scope, they seem to be more locally oriented than others, with around $40 \%$ of their customers coming from the same region as the gallery (a percentage that is significantly higher than that of Cluster 5), and they have the lowest percentage of foreign customers. They are also focused on small collectors, who account for slightly more than $50 \%$ of their customers. In sum, this strategy is characterized by a focus on various dimensions (customers, geo-graphic area, artists) and by a combination of cost and differentiation advantage.

Cluster 2: Differentiation strategy

This cluster encompasses 17 galleries (16\% of the sample) that were the largest in terms of number of employees (the average being 5.06 employees). They are characterized by a wide range of products and services, by a broad scope in terms of customers addressed (with diverse types of customer, both domestic and foreign), and by a service intensity (the number of services supplied) that is among the highest. Specifically, they are more oriented toward supplying face-to-face services (e.g., meetings with artists) than the others (significantly more than the galleries in Clusters 4 and 5). Considering the above elements, it is possible to classify their strategy as a differentiation strategy.

Cluster 3: Service-focused strategy

This cluster comprises 35 art galleries ( $34 \%$ of the sample), whose average size was 3.42 employees. The range of works they sell is medium-high, but this cluster is the one most characterized by service range and intensity (with a more intensive combination of seminars, meetings, cocktail events, and catalogue publications). This is why the strategy of these galleries has been termed service focused. The art galleries in this cluster specialize in large collectors ( $55 \%$ of their total customers), including both individuals and in-stitutions (for example, museums), without any geographic focus. Given the emphasis on services and the role of large collectors, this strategy can be considered a typical focus strategy.

Cluster 4: No-frills focus strategy

Only seven galleries ( $7 \%$ of the sample) belong to this group. These galleries are the smallest, with an average of 1.43 employees. For them, the primary market is dominant, and the minimum price charged is the lowest. Even the range of products is quite narrow, as is the range and intensity of services provided to customers. These strategy characteristics reveal that these firms are highly cost oriented. The galleries in Cluster 4 mainly target dealers and investors, which account for around 59\% of their total customers, showing that this is a strategy with a cost focus on a customer segment. 
Table 2. Summary statistics of variables used in cluster definition via PCA (mean, standard deviation, ANOVA F statistic, and significance).

\begin{tabular}{|c|c|c|c|c|c|c|c|c|c|c|c|c|c|}
\hline Cluster & & $\begin{array}{l}\text { Area (sq. } \\
\text { Meters) }\end{array}$ & $\begin{array}{c}\text { No. of } \\
\text { Branches }\end{array}$ & $\begin{array}{c}\text { Primary } \\
\text { Market } \\
(\%)\end{array}$ & $\begin{array}{l}\text { Minimum } \\
\text { Price }\end{array}$ & $\begin{array}{l}\text { No. of } \\
\text { Artists }\end{array}$ & $\begin{array}{l}\text { Range }^{a} \text { of } \\
\text { Artworks }\end{array}$ & $\begin{array}{l}\text { Range }{ }^{b} \text { of } \\
\text { Services }\end{array}$ & $\begin{array}{c}\text { Service } \\
\text { Intensity }^{c}\end{array}$ & $\begin{array}{c}\text { Large } \\
\text { Collectors } \\
(\%)\end{array}$ & $\begin{array}{c}\text { Investors } \\
(\%)\end{array}$ & $\begin{array}{c}\text { Small } \\
\text { Collectors } \\
(\%)\end{array}$ & $\begin{array}{c}\text { Occasional } \\
\text { Customers } \\
\quad(\%)\end{array}$ \\
\hline \multirow{2}{*}{1} & Mean & 262.5 & 1.12 & 87.41 & 1011.11 & 16.47 & 3.03 & 3.3 & 15.7 & 20.63 & 6.69 & 50.88 & 24.16 \\
\hline & SD & 410.8 & 0.33 & 25.48 & 836.35 & 8.63 & 1.96 & 1.16 & 9.45 & 19.23 & 8.4 & 23.72 & 23.27 \\
\hline \multirow{2}{*}{2} & Mean & 251 & 1.41 & 51.33 & 2138 & 51.35 & 5.65 & 4.35 & 19.75 & 40.75 & 20.31 & 27.25 & 13.63 \\
\hline & SD & 166.22 & 0.8 & 33.83 & 3074.17 & 45.01 & 1.93 & 1.27 & 8.79 & 20.25 & 13.16 & 21.09 & 13.4 \\
\hline \multirow{2}{*}{3} & Mean & 202.73 & 1.71 & 84.66 & 1479.17 & 18.73 & 4 & 5.14 & 23.94 & 55.47 & 14.06 & 22.66 & 7.78 \\
\hline & $\mathrm{SD}$ & 134.29 & 1.14 & 20.32 & 1242.91 & 7.91 & 1.88 & 1.12 & 21.24 & 17.05 & 11.44 & 14.55 & 7.01 \\
\hline 4 & SD & 65.28 & 0 & 17.29 & 1129.01 & 6.74 & 1.46 & 1 & 5.94 & 8.38 & 15.93 & 22.01 & 10.97 \\
\hline \multirow[b]{2}{*}{5} & Mean & 131.82 & 1.17 & 45.42 & 3227.27 & 18.11 & 3.08 & 3 & 8.42 & 68.42 & 10.83 & 11.92 & 7.17 \\
\hline & $\mathrm{SD}$ & 63.85 & 0.58 & 40.14 & 2705.21 & 12.88 & 1.16 & 1.13 & 3.8 & 15.22 & 11.08 & 6.97 & 7.83 \\
\hline \multirow{2}{*}{ Sample } & Mean & 217.5 & 1.36 & 75.8 & 1670.17 & 23.63 & 3.78 & 4.04 & 17.82 & 40.23 & 15.47 & 31 & 14.15 \\
\hline & SD & 258.24 & 0.81 & 31.38 & 1900.03 & 24 & 2.02 & 1.44 & 14.93 & 25.75 & 16.95 & 23.58 & 16.77 \\
\hline \multirow{2}{*}{ ANOVA } & $\mathrm{F}$ & 0.769 & 2.984 & 9.516 & 3.273 & 9.445 & 6.834 & 15.61 & 3.336 & 28.074 & 32.965 & 14.036 & 5.428 \\
\hline & Sig. & 0.548 & 0.023 & 0.000 & 0.015 & 0.000 & 0.000 & 0.000 & 0.014 & 0.000 & 0.000 & 0.000 & 0.001 \\
\hline
\end{tabular}

${ }^{a}$ Number of types of artwork offered by the gallery; ${ }^{b}$ Number of types of service offered by the gallery; ${ }^{c}$ Total number of services offered by the gallery in one year. 
Table 3. ANOVA on additional variables.

\begin{tabular}{|c|c|c|c|c|c|c|c|c|}
\hline & Cluster 1 & Cluster 2 & Cluster 3 & Cluster 4 & Cluster 5 & & & \\
\hline Size & $\mathrm{n} 1=33$ & $\mathrm{n} 2=17$ & $\mathrm{n} 3=35$ & $\mathrm{n} 4=7$ & $\mathrm{n} 5=12$ & & & \\
\hline Variables & & & Variables' means & & & $\mathrm{F}$ & $p$-value & Significant comparisons at alpha $=0.1$ \\
\hline No. of employees & 1.7 & 5.06 & 3.42 & 1.43 & 1.75 & 3.133 & 0.018 & (clu1, clu2) \\
\hline Customers: Italian (from other regions & $41 \%$ & $46 \%$ & $47 \%$ & $55 \%$ & $51 \%$ & 0.885 & 0.476 & \\
\hline Customers: Italian (from the same region) & $41 \%$ & $26 \%$ & $28 \%$ & $20 \%$ & $18 \%$ & 2.126 & 0.083 & (clu1, clu5) \\
\hline Services: seminars & $18 \%$ & $35 \%$ & $69 \%$ & $14 \%$ & $25 \%$ & 6.587 & 0.000 & $(\mathrm{clu} 1, \mathrm{clu} 3)(\mathrm{clu} 2, \mathrm{clu} 3)(\mathrm{clu} 3, \mathrm{clu} 4)(\mathrm{clu} 3, \mathrm{clu} 5)$ \\
\hline Services: meetings & $48 \%$ & $65 \%$ & $86 \%$ & $0 \%$ & $8 \%$ & 11.894 & 0.000 & $\begin{array}{l}\text { (clu1, clu3) (clu2, clu4) (clu1, clu5) (clu2, clu4 } \\
\text { (clu2, clu5) (clu3, clu4) (clu3, clu5) }\end{array}$ \\
\hline Services: cocktails & $73 \%$ & $88 \%$ & $91 \%$ & $57 \%$ & $58 \%$ & 2.623 & 0.039 & (clu3, clu5) \\
\hline Catalogues: exhibitions & $61 \%$ & $100 \%$ & $91 \%$ & $86 \%$ & $75 \%$ & 4.372 & 0.003 & (clu1, clu2) (clu1, clu3) \\
\hline Catalogues: artists' & $42 \%$ & $59 \%$ & $77 \%$ & $43 \%$ & $33 \%$ & 3.183 & 0.017 & (clu1, clu3) \\
\hline Communication: Facebook & $97 \%$ & $71 \%$ & $89 \%$ & $71 \%$ & $83 \%$ & 2.174 & 0.077 & (clu1, clu2) \\
\hline Communication: YouTube & $15 \%$ & $0 \%$ & $29 \%$ & $14 \%$ & $8 \%$ & 1.998 & 0.101 & $($ clu2, clu3) \\
\hline Competencies: artistic & $88 \%$ & $88 \%$ & $91 \%$ & $29 \%$ & $92 \%$ & 5.806 & 0.000 & $(\operatorname{clu} 1, \operatorname{clu} 4)(\operatorname{clu} 2, \operatorname{clu} 4)(\operatorname{clu} 3, \operatorname{clu} 4)(\operatorname{clu} 4, \operatorname{clu} 5)$ \\
\hline Competencies: art management & $64 \%$ & $82 \%$ & $79 \%$ & $43 \%$ & $58 \%$ & 1.658 & 0.166 & \\
\hline Competencies: sales/commercial & $76 \%$ & $82 \%$ & $71 \%$ & $71 \%$ & $83 \%$ & 0.324 & 0.862 & \\
\hline Competencies: marketing & $49 \%$ & $71 \%$ & $59 \%$ & $14 \%$ & $50 \%$ & 1.814 & 0.132 & \\
\hline Legal structure: unlimited & $41 \%$ & $29 \%$ & $33 \%$ & $29 \%$ & $33 \%$ & 0.206 & 0.935 & \\
\hline Cooperative agreements & $69 \%$ & $80 \%$ & $90 \%$ & $86 \%$ & $73 \%$ & 1.046 & 0.388 & \\
\hline Location: periphery & $24 \%$ & $6 \%$ & $11 \%$ & $14 \%$ & $25 \%$ & 1.032 & 0.395 & \\
\hline
\end{tabular}

${ }^{a}$ Number of distinct competencies possessed by the art gallery. 
Cluster 5: High-end niche strategy

The fifth cluster comprises 12 art galleries (11\% of the sample), with an average of 1.75 employees; the minimum price of the artworks they sell is the highest of the sample, while both the range and intensity of the services they provide are low. Their primary target (around 67\%) is represented by large collectors. Moreover, the galleries in Cluster 5 have the highest percentage of foreign customers (more than $30 \%$ ) and the lowest percentage of customers from the same region $(18 \%$, which is significantly lower than the percentage in Cluster 1). All these features suggest that these firms are focused on a high-end niche.

We find that the most popular strategies are focus and niche strategies (Clusters 1, 3, 4 , and 5), some of which combine cost and differentiation advantage (Cluster 1), but there are also galleries that implement a broad scope strategy (Cluster 2). Thus, HP1 is partially confirmed.

Considering that Cluster 5 is the only one populated by art galleries that implement a focus strategy, it was established as a benchmark in the study and compared to the others, which represent other strategies of our taxonomy. According to the estimates of the model (Table 4), the galleries belonging to Cluster 1 are almost four times more likely to grow than the galleries in Cluster 5, and their strategy (defined as cost and differentiation focus) is the only one that can be associated with expected growth. As the variable cooper-ative agreements is not significant, HP2 is not confirmed.

Table 4. Final estimates of logistic regression, dependent variable: possibility of future growth according to the galleries $(0$ $=$ "We don't think our sales will grow in the next three years/We think our sales will decrease"; $1=$ "We think our sales will increase in the next three years") ${ }^{\text {a }}$ with related classification table.

\begin{tabular}{|c|c|c|c|c|c|c|c|}
\hline & Step 15 & B & S.E. & Wald & df & Sign. & $\operatorname{Exp}(B)$ \\
\hline & Family gallery & -1.194 & 0.548 & 4.750 & 1 & 0.029 & 0.303 \\
\hline & Cluster $1=1$ & 1.342 & 0.561 & 5.712 & 1 & 0.017 & 3.826 \\
\hline & Marketing competencies & 0.896 & 0.530 & 2.857 & 1 & 0.091 & 2.449 \\
\hline & Sales competencies & -1.062 & 0.660 & 2.590 & 1 & 0.108 & 0.346 \\
\hline & Constant & 0.556 & 0.615 & 0.817 & 1 & 0.366 & 1.743 \\
\hline & \multirow{2}{*}{\multicolumn{2}{|c|}{ Classification $^{\mathrm{b}}$}} & $\begin{array}{r}\mathrm{P} \\
\text { Future }\end{array}$ & wing & \multirow{2}{*}{\multicolumn{3}{|c|}{ Percentage of correct classification }} \\
\hline & & & 0 & 1 & & & \\
\hline \multirow{3}{*}{ Observed } & \multirow{2}{*}{ Future sales growing } & 0 & 20 & 16 & \multirow{2}{*}{\multicolumn{3}{|c|}{55.6}} \\
\hline & & 1 & 11 & 34 & & & \\
\hline & \multicolumn{2}{|c|}{ Overall classification } & & & \multicolumn{3}{|c|}{66.7} \\
\hline
\end{tabular}

a Variables entered at Step 1: type of gallery; location (center/periphery); legal structure; ownership (family/non-family gallery); equity agreement, non-equity agreement, equity /non-equity agreement; Cluster $=1$, Cluster $=2$, Cluster $=3$, Cluster $=4$; marketing competencies; sales competencies; art management competencies; graphic/communication competencies; artistic competencies; gallery age; number of employees (in classes). ${ }^{\mathrm{b}}$ Cutoff at 0.5 .

When considering firm-specific structural factors (Table 4), our evidence shows that marketing competencies significantly and positively impact expected growth, while the role of sales competencies (which will not be further considered, as it is not statistically significant) tends to be negative. Moreover, family galleries have only one-third of the probability of growth as non-family ones. The other internal factors derived from the literature were not statistically significant in relation to growth in our sample. The model shows balanced prediction rates for each class (growing revenues: $72.1 \%$; stable/decreasing revenues: $60 \%$ ), with a tolerable total error rate $(33.3 \%)$.

\section{Discussion}

The strategies of the art galleries in our sample can be categorized as follows: cost and differentiation focus, service focus, differentiation, no-frills, and high-end niche. As a first contribution to theory, we confirm that the focus or niche strategies suggested by the few scholars who have studied competitive strategies in fragmented industries are also 
implemented in a fragmented cultural industry. Our taxonomy also includes broad scope strategies, but specifically a cluster populated by firms that implement a differentiation strategy. This could be explained by the need of firms competing in cultural industries to supply a number of products and services to address diverse customers with a rich value proposition. In addition, while one might assume that many art galleries operate in a specific, narrow geographic area, we find that some of the proactive art galleries we studied implemented focus strategies that are not geographically restricted, reaching customers from other regions and countries and thus demonstrating the ability to use limited resources to reach a broader geographic market. Our study also confirms the evidence of Leitner and Güldenberg [49] on the possibility of successfully combining cost and differentiation advantages, which is also underlined by Cappel et al. [83] for SMEs competing in service industries and by Miller and Dess [45] in the context of a combination of differentiation and price leadership. In sum, our study shows that art galleries, perhaps due to their mixed nature, follow strategies that are very similar to those of other profit organizations, with the exception of the cost leadership strategy, and that they have a differentiation orientation that we expect to be stronger than in other industries. Overall, our evidence supports the notions that galleries' very small size and the fragmentation of their industry are crucial in shaping their competitive posture and that their cultural nature affects the orientation to differentiation. From the contingency perspective, our results indicate that there is a fit between strategies based on differentiation and the cultural nature of art galleries. Similarly, we find a fit between focus and niche strategies of micro and small-sized firms and the fragmentation of the industry where art galleries compete. A cost leadership strategy, instead, is not implemented by proactive art galleries in this industry, basically because it is not coherent with the need to address different customers' tastes (typical of a cultural industry).

A second contribution of this study is to the literature on the growth of SMEs and micro firms, which we address from the point of view of the strategies and internal factors affecting growth. From this perspective, the first finding of the study is that, of the five strategies we identified, only the one that combines cost and differentiation advantage is associated with expected sales growth. This result confirms that differentiation is important and suggests that a cost-focused strategy is not enough to ensure growth, perhaps because a strong focus on cost (and consequently on prices) affects the reach of art galleries, limiting their potential to reach diverse customer segments that are fundamental to growth. This is particularly true for those galleries that, having a narrow geographical scope, can grow only by reaching new customer segments.

The idea that a focus on costs is not enough to ensure growth is supported by a comparison with the evidence of a study by Bamiatzi and Kirchmaier [84] on SMEs competing under adverse conditions. This is based on the assumption that, because of the difficulties of coping with fragmentation, firms competing in fragmented industries may share certain strategies with firms competing under adverse conditions. Bamiatzi and Kirchmaier [84] identify various strategies of high-growth SMEs and classify them based on four strategic themes: focus on cost, focus on differentiation, focus on customization, and focus on internationalization (with each containing various sub-strategies). What emerges from the comparison of our and their results is that some of the strategies in our taxonomy echo some of those identified by Bamiatzi and Kirchmaier [84] when looking at the growth strategies of SMEs in declining markets, but we did not find a complete overlap. Most significantly, we do not have a cluster that is strongly focused on international customers, even though the galleries in Cluster 5 are more internationally oriented than the others. However, our results reveal that a single strategy is not sufficient to grow in the art gallery industry, reflecting Bamiatzi and Kirchmaier's [84] (p. 277) statement that "a single strategy appears insufficient to beat a declining market for long".

Looking at growth strategies, we also find that growth-oriented art galleries are not different from others in terms of consolidation. Indeed, the variable cooperative agreements does not characterize any specific strategy but characterizes the whole industry. This 
is consistent with the literature on the consolidation of fragmented industries and with studies (for example, Gundolf et al. [85]) that have underlined the importance of alliances for micro firms in cultural and creative industries.

A further finding of the study is the identification of firm-specific structural factors that, in addition to strategy type, can enhance or hinder growth. The evidence suggests that these factors are few. Independently of the clusters and, therefore, of the strategies implemented, the presence of more sophisticated competencies (namely, marketing competencies) is positively correlated with growth. The more the internet becomes the channel through which art galleries reach customers and, in part, sell their products, the less the traditional competencies are important for differentiating firms from competitors; instead, the effective use of marketing tools and the development of marketing competencies become necessary to successfully compete in such a difficult environment. This is not new in the literature on the growth of firms and on SMEs facing a consolidation trend in a fragmented industry $[51,67,86]$, but it is quite new in the context of art galleries. Furthermore, we find that family ownership of a gallery reduces the odds of growth by two-thirds compared to non-family-owned galleries. In other words, family-owned art galleries are much less oriented toward growth than those that are not family owned, which confirms the results of other studies on family businesses [25,87]. The literature on family businesses posits that family firms may deliberately limit growth to avoid the involvement of external investors, to reduce risk, and to pursue the firm's survival to preserve socioemotional wealth [88]. This would also be the case for the art galleries in our sample.

\section{Implications for Practitioners and Policy Makers}

The results of our study let us draw implications both for practitioners and policy makers, who can improve art galleries' sustainability through decisions, advice, and specific policies. First, art galleries should be supported to leverage on the increasing importance of IT both for direct sales (e-commerce) and as a marketing tool. Indeed, art galleries seeking growth should develop marketing and technological competencies to improve communication and increase value for customers, a goal not easy to achieve in an industry that has traditionally been driven by artistic and sales competencies. This shift is, however, necessary as, in line with the contingency approach, when the environment changes, firm structural characteristics (in this case, specific competences) also need to change to find a new fit. Second, they should also acquire or develop managerial competencies, as these become crucial for cost control. One innovative way to achieve a balance between costs, prices, and value for customers can be found in using the internet and social networks to attract customers, supply some services (for example, meetings with artists or virtual studio visits), and sell some artworks online, as this allows firms to be located outside the city center, thus reducing the cost of space rental and increasing sales per employee. The art galleries in Cluster 1 actually use Facebook extensively and have few employees, and almost $25 \%$ of them (vs. $5.9 \%$ of the galleries in Cluster 2) are located outside the city center. This means that, although location was not found to be correlated to growth in our study, it could play an indirect role as a lever to implement a strategy oriented toward growth. Moreover, galleries could save money on non-strategic resources and invest in more strategic ones like personnel, thus increasing their competences. Further, galleries could more and more share some resources (for example space) with partners, thus reducing rental costs.

Moving from the role of competencies to that of ownership from the perspective of growth, it is necessary to stress that certain actions should be taken when family-owned art galleries wish to grow, primarily involving non-family members in the business and developing new competencies. This could offset their inertia in regard to strategy innovations and give them a chance to grow even while competing in a difficult environment. This reflects what family-owned firms in other industries must do to overcome the constraints deriving from their ownership. It is well known, however, that this is not easy to do. In sum, the three most important suggestions for art galleries' owners, managers, and advisors are 
to invest in developing marketing competencies, increase the use of the internet, and be open to people who are not family members. This could also be achieved through initially non-equity cooperative agreements that could eventually evolve into equity alliances.

The growth of art galleries is important not only to them but also to policy makers, because, as LaMore et al. [89] note, a community's creative and cultural assets have effects as job generators, innovative business facilitators, and stimulators of future workers' creative capacities. It is critical, however, that local and national governments identify which SMEs and micro firms are the most oriented toward growth, as not all small firms can have a positive economic impact. Rather, only a few are able to contribute to the creation of new jobs [90-93]. To help art galleries to develop the competencies they need, they could be provided with affordable consultancy or educational programs focused on marketing (e.g., on the use of specific marketing tools for customer relationship management and on the development of websites). Indeed, for micro firms, the pervasiveness of IT is simultaneously a concern and a key opportunity because of the increasing importance of e-commerce [94]. Furthermore, art galleries could be involved in programs for family businesses that help them to adopt a new mentality and increase their openness to people who are not family members. Of course, more traditional tools, such as easier access to financial resources, could also strengthen art galleries on the condition of being associated with managerial education or specific mentoring programs. Lastly, art galleries could be helped to reach agreements with other art galleries, as such agreements appear to be relevant to competing in the industry.

\section{Conclusions}

This study was conducted to understand which competitive strategies are employed by an Italian sample of proactive art galleries as well as which of these strategies and which firm-specific factors are associated with expected growth. This is relevant for the sustainability of art galleries and their contributions to the economic, social, and cultural development of the areas where they are located. From a theoretical point of view, this study provides an original contribution to filling the gaps related to the scarcity of empirical research on SMEs and particularly on the factors that affect their growth. In addition, taking a contingency perspective, it offers a deeper understanding of an industry that is understudied from a strategic point of view.

We contribute to the extant literature in various ways. First, we provide a typology of competitive strategies in a fragmented cultural industry and examine them from the vantage of existing theory on competitive strategies for fragmented industries. Although cultural industries have specific features, we find that the most relevant competitive strategies for firms competing in other fragmented industries are also implemented by art galleries, even though a differentiation orientation appears to be widespread. Therefore, from the contingency theory perspective, our results confirm the necessary fit between the fragmented nature of the art gallery industry (environmental factor) and the strategic and structural characteristics of proactive art galleries that implement focus or niche strategies. On the other side, our evidence shows that a fit exists between the cultural feature of the industry and the proactive art galleries' orientation to differentiation and to networking (a way to have a broader range of products and a richer value proposition to satisfy customers' needs). The study thus contributes to the contingency theory, testing its effects in an understudied context. Furthermore, through the identification of the competitive strategy that is associated to growth-oriented art galleries (a cost and differentiation focus strategy), we contribute to the literature on the growth of SMEs and micro firms and at the same time answer the call of Singh et al. [16] for empirical research on SMEs. Our research on art galleries also identifies managerial and policy implications. Art galleries make cities more livable, colorful, and enjoyable, making art accessible to everyone and enhancing art tourism [95]. As such, they are a very important component of the modern and contemporary art system, and their sociocultural role is relevant both from the artists perspective (as they play as artists' gatekeepers) and from the public point of view as 
they offer chances of meeting artists, especially the young and less known ones. Indeed, galleries, and in particular the ones who operate in the primary market, are between "unknown artist and ignorant potential buyes" [96]. Further, art galleries can contribute to improving the quality of urban areas and mainly of suburbs. Nowadays, also leveraging on opportunities offered by IT, it is possible to locate art galleries out of the city centers, thus helping poorer and less educated people to get close to art and cultural events. This could contribute to enhancing the cultural consciousness of people, making suburbs more beautiful, and attracting tourists to areas that are not traditionally included in their tours. Policy makers at the local level should therefore help galleries to grow and be sustainable over time by implementing some of the policies our research has suggested. This will not only serve to create art districts and economic regeneration but also to stimulate small businesses [97] to renew peripheric areas and boroughs under the economic and cultural point of view, thus enhancing proximity tourism.

This study is not without limitations. First, it was conducted on a sample of firms from the same country. As Italy is one of the world's more active art markets [98], however, and as the art gallery industry is fragmented globally, we hope these results will inspire research in other countries and among other samples of firms. In addition, our sample was not very large, which may have influenced the ANOVA significance of some variables. Finally, as with all studies that look at the future, ours was based on expectations and not on actual sales growth data. Nevertheless, perceptions of increases in sales/revenue have proven to be highly correlated to actual growth in sales/revenue $[99,100]$, and we used such perceptions consistently with previous studies.

In regard to future research directions, the results of this early study could first be tested using broader and more international samples. Second, studies could be developed to analyze the effectiveness of strategies that combine cost and differentiation advantage in standalone firms as compared to firms that are allied with others, and further research could examine the relationships between the competitive strategies identified in this work and a firm's actual growth. The evidence from such studies could help to test and advance theories in this area while also supporting policy makers in enhancing the growth of SMEs and micro firms in this and other fragmented industries.

Author Contributions: Conceptualization, D.D. and G.M.; investigation, G.M.; methodology and data analysis, L.C. and C.L.; writing-original draft, D.D., G.M., L.C., and C.L.; writing-review and editing, D.D., G.M., L.C., and C.L.; supervision D.D. All authors have read and agreed to the published version of the manuscript.

Funding: This research received no external funding.

Institutional Review Board Statement: Not applicable.

Informed Consent Statement: Informed consent was obtained from all subjects involved in the study.

Data Availability Statement: The data presented in this study are available on request from the corresponding author.

Conflicts of Interest: The authors declare no conflict of interest.

\section{References}

1. Gherghina, S.C.; Botezatu, M.A.; Hosszu, A.; Simionescu, L.N. Small and Medium-Sized Enterprises (SMEs): The Engine of Economic Growth through Investments and Innovation. Sustainability 2020, 12, 347. [CrossRef]

2. Che Nawi, N.; Al Mamun, A.; Daud, R.R.R.; Nasir, N.A.M. Strategic Orientations and Absorptive Capacity on Economic and Environmental Sustainability: A Study among the Batik Small and Medium Enterprises in Malaysia. Sustainability 2020, $12,8957$. [CrossRef]

3. OECD. Enhancing the Contributions of SMEs in a Global and Digitalised Economy; OECD: Paris, France, 2017; pp. 2-21. Available online: https:/ /www.oecd.org/industry/C-MIN-2017-8-EN.pdf (accessed on 21 December 2020).

4. Brambilla, M.; Michelangeli, A.; Peluso, E. Equity in the City: On Measuring Urban (Ine)quality of Life. Urban Stud. 2013, 50, 3205-3224. [CrossRef]

5. Roback, J. Wages, Rents, and the Quality of Life. J. Political Econ. 1982, 90, 1257-1278. [CrossRef] 
6. Munro, E. Building soft skills in the creative economy: Creative intermediaries, business support and the "soft skills gap". Poetics 2017, 64, 14-25. [CrossRef]

7. Grimmer, L.; Miles, M.P.; Byron, J.; Grimmer, M. The impact of resources and strategic orientation on small retail firm performance. J. Small Bus. Manag. 2017, 55, 7-26. [CrossRef]

8. Jaramillo, J.A.; Zharta Sossa, J.W.; Orozco Mendoza, G.L. Barriers to sustainability for small and medium enterprises in the framework of sustainable development-Literature review. Bus. Strategy Environ. 2019, 28, 512-524.

9. Torres, A.M. Marketing networks as a form of strategic alliance among craft enterprises. Int. J. Nonprofit Volunt. Sect. Mark. 2002, 7, 229-243. [CrossRef]

10. Hirsch, P.M. Cultural Industries Revisited. Organ. Sci. 2000, 11, 356-361. [CrossRef]

11. Peltoniemi, M. Cultural Industries: Product-Market Characteristics, Management Challenges and Industry Dynamics. Int. J. Manag. Rev. 2015, 17, 41-68. [CrossRef]

12. European Commission. Unlocking the Potential of Cultural and Creative Industries-GreenPaper; European Commission: Brussels, Belgium, 2010.

13. European Commission. Commission Reccomendation of 6 May 2003 Concerning the Definition of Micro, Small and Medium-Sized Entreprises; European Commission: Brussels, Belgium, 2003.

14. Porter, M.E. Competitive Strategy: Techniques for Analyzing Industries and Competitors; Free Press: New York, NY, USA, 1980.

15. Shuman, J.C.; Seeger, J.A. The Theory and Practice of Strategic Management in Smaller Rapid Growth Firms. Am. J. Small Bus. 1986, 11, 7-18. [CrossRef]

16. Singh, R.K.; Garg, S.K.; Deshmukh, S.G. Strategy Development by SMEs for competitiveness: A review. Benchmarking 2008, 15, 525-547. [CrossRef]

17. Roodhouse, S. Creative industries: The business of definition and cultural management practice. Int. J. Arts Manag. 2008, 11, 16-27.

18. TEFAF. Art Market Report 2017; The European Fine Art Foundation (TEFAF): Helvoirt, The Netherlands, 2017.

19. Borch, O.J.; Bradstad, B. Strategic turnaround in a fragmented industry. J. Small Bus. Enterp. Dev. 2003, 10, 393-407. [CrossRef]

20. Dollinger, M.J. The Evolution of Collective Strategies in Fragmented Industries. Acad. Manag. Rev. 1990, 15, 266-285. [CrossRef]

21. Hill, C.W.L.; Jones, G.R. Essential of Strategic Management, 2nd ed.; South-Western Pub.: Mason, OH, USA, 2009.

22. Davidsson, P.; Kirchhoff, B.; Hatemi, J.; Gustavsson, H. Empirical Analysis of Business Growth Factors Using Swedish Data. J. Small Bus. Manag. 2002, 40, 332-349. [CrossRef]

23. Garcés-Galdeano, L.; Garcia-Olaverri, C. How important is family business involvement for small companies' growth? J. Small Bus. Enterp. Dev. 2020, 27, 531-554. [CrossRef]

24. Gupta, P.D.; Guha, S.; Krishnaswami, S.S. Firm growth and its determinants. J. Innov. Entrep. 2013, 2, 15. [CrossRef]

25. Hamelin, A. Influence of family ownership on small business growth. Evidence from French SMEs. Small Bus. Econ. 2013, 41, 563-579. [CrossRef]

26. Badia, F.; Schiano Lo Moriello, V. Evolution of the business models for contemporary art galleries. Current situation and future challenges. In Proceedings of the IFKAD Culture, Innovation and Entrepreneurship: Connecting the Knowledge Dots, Bari, Italy, 10-12 June 2015; Arts for Business: London, UK, 2015; pp. 1567-1581.

27. Resch, M.B.F. Management of Art Galleries-Business Model. Ph.D. Thesis, University of St. Gallen, St. Gallen, Switzerland, 13 May 2011.

28. Mateos-Ronco, A.; Torralba, N.P. Sustainable Management of Contemporary Art Galleries: A Delphi Survey for the Spanish Art Market. Sustainability 2019, 11, 541. [CrossRef]

29. European Union. Boosting the Competitiveness of Cultural and Creative Industries for Growth and Jobs; European Commission: Brussels, Belgium, 2016.

30. Carpano, C.; Chrismas, J.J.; Roth, K. International Strategy and Environment: An Assessment of the Performance Relationship. J. Int. Bus. Stud. 1994, 25, 639-656. [CrossRef]

31. Robertson, I.; Chong, D. (Eds.) The Art Business; Routledge: London, UK; New York, NY, USA, 2008.

32. Sotheby's. Annual Report; Sotheby's: New York, NY, USA, 2007.

33. McCarthy, K.F.; Ondaatje, A.H.; Brooks, A.; Szanto, A. A Portrait of the Visula Arts: Meeting the Challenges of a Nerw Era; The Rand Corporation: Santa Monica, CA, USA, 2005.

34. Stellweg, C. Gallerists and the marketplace. In Taking AIM; Nieves, M., Ed.; Co published with The Bronx Museum of the Arts; Fordham University Press: New York, NY, USA, 2011; pp. 89-99.

35. Cameron, S.; Coaffee, J. Art, gentrification and regeneration-From artist as pioneer to public arts. Eur. J. Hous. Policy 2005, 5, 39-58. [CrossRef]

36. Barata-Salgueiro, T.; Guimarães, P. Public Policy for Sustainability and Retail Resilience in Lisbon City Center. Sustainability 2020, 12, 9433. [CrossRef]

37. Caves, R.E. Creative Industries; Harvard University Press: Cambridge/London, UK, 2000.

38. Crane, D. Reward System in Art, Science, Religion. Am. Behav. Sci. 1976, 19, 719-734. [CrossRef]

39. Wright, P.; Ferris, S.P.; Vaughan, M.J.; Jackson, W.T. Are competitors advantageous or disadvantageous in consolidated versus fragmented industries? Acad. Strateg. Manag. J. 2004, 3, 47-64.

40. Hofer, C.W. Toward a contingency theory of business strategy. Acad. Manag. J. 1975, 18, 784-810. [CrossRef] 
41. Fiedler, F.A. A contingency model of leadership effectiveness. In Advances in Experimental Social Psychology; Berkowitz, L., Ed.; Academic Press: New York, NY, USA, 1964.

42. Chandler, A.D. Strategy and Structure; The MIT Press: Cambridge, MA, USA, 1962.

43. Venkatraman, N. The concept of fit in strategy research: Towards verbal and statistical correspondence. Acad. Manag. Rev. 1989, 14, 423-444. [CrossRef]

44. Donaldson, L. Strategy and structural adjustment to regain fit and performance: In defense of contingency theory. J. Manag. Stud. 1987, 24, 1-24. [CrossRef]

45. Kelliher, F.; Reinl, L. A resource-based view of micro-firm management practice. J. Small Bus. Enterp. Dev. 2009, 16, 521-532. [CrossRef]

46. Watkin, D.G. Toward a competitive advantage: A focus strategy for small retailers. J. Small Bus. Manag. 1986, 10, 9-15.

47. Perry, C. Growth strategies for small firms: Principles and case studies. Int. Small Bus. J. 1987, 5, 17-25. [CrossRef]

48. Parnell, J.A.; Lester, D.L.; Long, Z.; Köseoglu, M.A. How environmental uncertainty affects the link between business strategy and performance in SMEs: Evidence from China, Turkey, and the USA. Manag. Dec. 2012, 50, 546-568. [CrossRef]

49. Leitner, K.-H.; Güldenberg, S. Generic strategies and firm performance in SMEs: A longitudinal study of Austrian SMEs. Small Bus. Econ. 2010, 35, 169-189. [CrossRef]

50. Miller, G.; Dess, A. Strategic Management; Mc Graw Hill International Editions: New York, NY, USA, 1993.

51. Bahadir, S.C.; Bharadwaj, S.; Parzen, M. A meta-analysis of the determinants of organic sales growth. Int. J. Res. Mark. 2009, 26, 263-275. [CrossRef]

52. Brenner, T.; Schimke, A. Growth Development Paths of Firms-A Study of Smaller Businesses. J. Small Bus. Manag. 2015, 53, 539-557. [CrossRef]

53. Storey, D. Understanding the Small Business Sector; Routledge: London, UK; New York, NY, USA, 1994.

54. Orser, B.J.; Hogarth-Scott, S.; Riding, A.L. Performance, firm size, and management problem solving. J. Small Bus. Manag. 2000, $38,42-58$.

55. Almus, M.; Nerlinger, E.A. Growth of New Technology-Based Firms: Which Factors Matter? Small Bus. Econ. 1999, 13, 141-154. [CrossRef]

56. Wijewardena, H.; Tibbits, G.E. Factors Contributing to the Growth of Small Manufacturing Firms: Data from Australia. J. Small Bus. Manag. 1999, 37, 88-96.

57. Nunes, P.M.; Gonçalves, M.; Serrasqueiro, Z. The influence of age on SMEs' growth determinants: Empirical evidence. Small Bus. Econ. 2013, 40, 249-272. [CrossRef]

58. Bentzen, J.; Madsen, E.S.; Smith, V. Do firms' growth rates depend on firm size? Small Bus Econ. 2012, 39, 937-947. [CrossRef]

59. Davidsson, P.; Achtenhagen, L.; Naldi, L. Research on Small Firm Growth: A Review. In Proceedings of the 35th EISB Conference: Sustaining the Entrepreneurial Spirit over Time: Implications for Young Companies, Family Businesses, and Established Companies, Barcelona, Spain, 12-14 September 2005; Prats, J., Velamuri, R., Eds.; IESE Business School: Barcelona, Spain, 2005; pp. 1-27.

60. Karlsson, J. Firm size and growth barriers: A data-driven approach. Small Bus. Econ. 2000, 5. [CrossRef]

61. Mohr, V.; Garnsey, E.; Theyel, G. The role of alliances in the early development of high-growth firms. Ind. Corp. Chang. 2014, 23, 233-259. [CrossRef]

62. Kuo, R.; Chi, S.; Kao, S. A Decision Support System for Selecting Convenience Store Location through Integration of Fuzzy AHP and Artificial Neural Network. Comput. Ind. 2002, 47, 199-214. [CrossRef]

63. Litz, R.A.; Rajaguru, G. Does small store location matter? A test of three classic theories on retail location. J. Small Bus. Enterp. 2008, 21, 477-492. [CrossRef]

64. De Massis, A.; Kotlar, J.; Chua, J.H.; Chrisman, J.J. Ability and willingness as sufficiency conditions for family-oriented particularistic behavior: Implications for theory and empirical studies. J. Small Bus. Manag. 2014, 52, 344-364. [CrossRef]

65. Gomez-Mejia, L.R.; Haynes, K.T.; Nunez-Nickel, M.; Jacobson, K.J.L.; Moyano-Fuentes, J. Socioemotional wealth and business risks in family-controlled firms: Evidence from Spanish olive oil mills. Adm. Sci. Q. 2007, 52, 106-137. [CrossRef]

66. Barney, J.B. Firm Resources and sustained competitive advantage. J. Manag. 1991, 17, 99-120. [CrossRef]

67. McGee, J.E.; Shook, C.L. Responding to industry consolidation in fragmented industries: The role of capabilities in small business survival. J. Small Bus. Strategy 2000, 11, 21-32.

68. Reijnders Will, J.M.; Verhallen Theo, M.M. Strategic alliances among small retailing firms: Empirical evidence for the Netherlands J. Small Bus. Manag. 1996, 34, 36-45.

69. Thompson, D. The $\$ 12$ Million Stuffed Shark: The Curious Economics of Contemporary Art; Palgrave Mcmillan: New York, NY, USA, 2008.

70. Infocamere. Database; Imprese; Infocamere: Roma, Italy, 2018.

71. Available online: https://www.artissima.art/ (accessed on 5 October 2017).

72. Available online: http:/ / www.miart.it/ (accessed on 5 October 2017).

73. Available online: https:/ / miafair.it/ (accessed on 5 October 2017).

74. Available online: http://www.artefiera.it/home/776.html (accessed on 5 October 2017).

75. Available online: https://artverona.it/ (accessed on 5 October 2017). 
76. Özleblebicia, Z.; Çetin, S. The role of managerial perception within strategic management: An exploratory overview of the literature. Procedia Soc. Behav. Sci. 2015, 207, 296-305. [CrossRef]

77. Ketchen, D.J.; Shook, C.L. The application of cluster analysis in strategic management research: An analysis and critique. Strateg. Manag. J. 1996, 17, 441-458. [CrossRef]

78. Ding, C.; He, X. K-means clustering via principal component analysis. In Proceedings of the Twenty-First International Conference on Machine Learning (ICML'04), Banff, AB, Canada, 4-8 July 2004; ACM: New York, NY, USA, 2004; pp. 29-38.

79. Lebart, L.; Morineau, A.; Piron, M. Statistique Exploratoire Multidimensionnelle; Dunod: Paris, France, 1995.

80. Rousseeuw, P.J. A visual display for hierarchical classification. In Data Analysis and Informatics; Diday, E., Escoufier, Y., Lebart, L., Pages, J., Schektman, Y., Tomassone, R., Eds.; North-Holland Publishing: Amsterdam, The Netherlands, 1986; Volume 4, pp. 743-748.

81. Achtenhagen, L.; Ekberg, S.; Melander, A. Fostering growth through business development: Core activities and challenges for micro-firm entrepreneurs. J. Manag. Organ. 2017, 23, 167-185. [CrossRef]

82. Steyerberg, W.E.; Eijkemans, M.J.C.; Habbema, J.D.F. Stepwise Selection in Small Data Sets: A Simulation Study of Bias in Logistic Regression Analysis. J. Clin. Epidemiol. 1999, 52, 935-942. [CrossRef]

83. Cappel, S.; Wright, P.; Kroll, M.; Wyld, D. Competitive strategies and business performance. An empirical study of select service businesses. Int. J. Manag. 1992, 9, 1-11.

84. Bamiatzi, V.C.; Kirchmaier, T. Strategies for superior performance under adverse conditions: A focus on small and medium-sized high-growth firms. Int. Small Bus. J. 2014, 32, 259-284. [CrossRef]

85. Gundolf, K.; Jaouen, A.; Gast, J. Motives for strategic alliances in cultural and creative industries. Creat. Innov. Manag. 2018, 27, 148-160. [CrossRef]

86. Nikunen, T.; Saarela, M.; Oikarinen, E.-L.; Muhos, M.; Isohella, L. Micro Enterprises' Digital Marketing Tools for Building Customer Relationships. Management 2017, 12, 171-188. [CrossRef]

87. Brush, C.G.; Ceru, D.J.; Blackburn, R. Pathways to entrepreneurial growth: The influence of management, marketing, and money. Bus. Horiz. 2009, 52, 481-491. [CrossRef]

88. Chen, Q.; Hou, W.; Wilson, C.; Wu, Z. Family Control, Regulatory Environment, and the Growth of Entrepreneurial Firms. Corp. Gov. 2014, 22, 132-144. [CrossRef]

89. La More, R.; Root-Bernstein, R.; Root-Bernstein, M.; Schweitzer, J.H.; Lawton, J.L.; Roraback, E.; Peruski, A.; VanDyke, M.; Fernandez, L. Arts and crafts: Critical to economic innovation. Econ. Dev. Q. 2013, 27, 221-229. [CrossRef]

90. Burns, P.; Dewhurst, J. (Eds.) Small Business and Entrepreneurship; MacMillan Business: Basingstoke, UK, 1996.

91. Glancey, K. Determinants of Growth and Profitability in Small Entrepreneurial Firms. Int. J. Entrep. Behav. Res. 1998, 4, 18-27. [CrossRef]

92. Morrison, A.; Breen, J.; Ali, S. Small Business Growth: Intention, Ability, and Opportunity. J. Small Bus. Manag. 2003, 41, 417-425. [CrossRef]

93. Stanworth, J.; Curran, J. Growth and the Smaller Firm—An Alternative View. J. Manag. Stud. 1976, 13, 95-110. [CrossRef]

94. Dutta, S.; Evrard, P. Information Technology and Organisation within European Small Enterprises. Eur. Manag. J. 1999, 17, 239-251. [CrossRef]

95. Franklin, A. Art tourism: A new field for tourist studies. Tour. Stud. 2018, 18, 399-416. [CrossRef]

96. Prinz, A.; Piening, J.; Ehrmann, T. The success of art galleries: A dynamic model with competition and information effects. J. Cult. Econ. 2015, 39, 153-176. [CrossRef]

97. Smith, H.L.; Discenza, R.; Baker, K.G. Building sustainable success in art galleries: An exploratory study of adaptive strategies. J. Small Bus. Strategy 2006, 16, 29-41.

98. McAndrew, C. The Art Market 2018; Art Basel-UBS: Basel, Switzerland, 2018.

99. Dess, G.G.; Robinson, R.B., Jr. Measuring organizational performance in the absence of objective measures: The case of the privately-held firm and conglomerate business unit. Strateg. Manag. J. 1984, 5, 265-273. [CrossRef]

100. Wach, D.; Stephan, U.; Gorgievski, M.J.; Wegge, J. Entrepreneurs' achieved success: Developing a multi-faceted measure. Int. Entrep. Manag. J. 2020, 16, 1123-1151. [CrossRef] 